\title{
A simple explanation of the relative performance evaluation puzzle
}

\author{
Marco Celentani $^{\mathrm{a}, *}$, Rosa Loveira ${ }^{\mathrm{b}}$ \\ a Department of Economics, Universidad Carlos III, Getafe (Madrid) 28903, Spain \\ ${ }^{\mathrm{b}}$ Departamento de Economía Cuantitativa, Universidad Complutense de Madrid, Campus de Somosaguas, \\ Pozuelo de Alarcón (Madrid) 28223, Spain
}

\begin{abstract}
We study a simple moral hazard model in which two risk-neutral owners establish incentives for their risk-averse managers to exert effort. Because the probability distributions over output realizations depend on a common aggregate shock, optimal contracts make the compensation of each manager contingent on own performance but also on a performance benchmark - the performance of the other firm. If the marginal return of effort depends on the aggregate state, optimal contracts are not monotonically decreasing in the performance benchmark. This provides a simple explanation of the Relative Performance Evaluation (RPE) Puzzle - the documented lack of a negative relationship between CEO compensation and comparative performance measures, such as industry or market performance. Our simple model can also explain one-sided RPE - the documented tendency to insulate a CEO's rewards from bad luck, but not from good luck. We clarify that our results are robust in several dimensions and we discuss other applications of our findings.
\end{abstract}

JEL classification: C72; D82; M52

Keywords: Relative performance evaluation; Optimal contracts; Executive compensation

is Marco Celentani acknowledges the financial support of Fundación BBVA. Marco Celentani and Rosa Loveira acknowledge the financial support of project BEC2002-03715 of Ministerio de Ciencia y Tecnología and of project SEJ2005-08462 of Ministerio de Educación y Ciencia.

* Corresponding author. Fax: +34 916249875.

E-mail addresses: marco.celentani@uc3m.es (M. Celentani), rloveira@ccee.ucm.es (R. Loveira). 


\section{Introduction}

The use of relative performance evaluation (RPE) provisions in executive compensation packages is consistently recommended in the academic and the business press. Several authors believe that making executive compensation increasing in own performance and decreasing in an appropriately defined performance benchmark would prevent managers from being rewarded or penalized for events they do not control, such as market movements or changes in interest rates. ${ }^{1}$

For all the praise that is heaped upon RPE, there is agreement that the extensive empirical research has produced scarce evidence in its favor in executive compensation-a stylized fact that has been termed the "RPE puzzle." 2 The scarcity of RPE in executive compensation has also been noted by the business and financial commentators who have been quick to condemn it as a suboptimal practice. ${ }^{3}$

To be sure, recent empirical research has found that performance benchmarking in top executive compensation is not absent altogether, but is asymmetric. Garvey and Milbourn (2006), for example, "find evidence that executives are [...] insulated from bad luck, while they are rewarded for good luck." ${ }^{4}$ For Bannister and Newman (2003) "many firms filter out negativeperformance-related events, but not positive ones. This is equivalent to using one-sided RPE, where a firm excuses the CEO from factors that affect industry performance adversely, but credits the CEO for factors that aid industry performance." ${ }^{5}$ An often-noted example of this type of asymmetric benchmarking, or one-sided RPE, is the practice of lowering the exercise price of executive stock options after stock prices decline but not increasing it when stock prices go up. ${ }^{6}$

The purpose of this paper is to show that the empirical evidence can be explained by a standard moral hazard model if the marginal returns of managerial effort depend on an aggregate state. In our baseline analysis, we consider a moral hazard environment in which two risk-neutral firm owners employ two risk-averse managers and in which output realizations are publicly observable. Because the distributions over output realizations depend on managerial effort but also on an unobservable common aggregate state, equilibrium contracts make the pay of each manager contingent on his performance (his output) and on a performance benchmark (the output of the other manager). Notice that the realization of each manager's output is independent of the other manager's effort choice, but the realization of the other manager's output conveys information relative to the likely aggregate state.

We study the optimal contracts which induce the managers to exert effort. As customary in the moral hazard literature, the optimal contract evokes a statistical interpretation, because it makes a larger payment when the observed realization leads to a large likelihood of the manager having exerted effort. In the environment we describe, however, the likelihood of a manager having exerted effort may be higher when the other manager succeeds than when he experiences a failure. This occurs, for instance, if the marginal return of effort is increasing in the aggregate

\footnotetext{
${ }^{1}$ See, for example, Rappaport (1999), Dobbs and Koller (2000), The Economist (2002), The Financial Economist Roundtable (2003), or Bebchuk (2006).

2 See, for instance, Antle and Smith (1986), Gibbons and Murphy (1990), Barro and Barro (1990), Janakiraman et al. (1992), Hall and Liebman (1998), Joh (1999), Aggarwal and Samwick (1999a, 1999b) or the surveys of Rosen (1992), Abowd and Kaplan (1999), Murphy (1999), and Prendergast (1999).

3 See, for instance, The Economist (2002) and de Swaan and Harper (2003).

4 Garvey and Milbourn (2006, p. 3).

5 Bannister and Newman (2003, p. 235).

6 See, for instance, Chance et al. (2000) and Garvey and Milbourn (2006).
} 
state, i.e., if exerting effort increases the probability of success sufficiently more in the favorable than in the unfavorable aggregate state.

To see why, notice first that if the marginal return of effort is increasing in the aggregate state, when manager 1's output is high, the likelihood of him having exerted effort is higher when the aggregate state is favorable than when it is unfavorable. But because a high level of output of manager 2 indicates that a favorable aggregate state is more likely, the likelihood of manager 1 having exerted effort is higher when both outputs are high than when his output is high and manager 2's is low.

Therefore, if the marginal returns of managerial effort are increasing in the aggregate state, equilibrium contracts exhibit one-sided RPE, because a manager's pay is decreasing in the performance benchmark when own performance is bad but increasing when it is good.

The same results can be obtained in a number of similar environments. For example, our qualitative results are unchanged when the aggregate state is observable. The same results are also obtained if adverse selection rather than moral hazard is the source of the agency problem. In this case, the result is obtained, for instance, if the increase in the probability of success that a good manager generates is larger in the favorable rather than the unfavorable aggregate state.

Our results are obtained for a very stylized description of a managerial agency relationship. But, because we make use of a very standard agency model, simple relabeling makes our results applicable to different environments in which individual performance is evaluated in relation to public observables, with examples ranging from yardstick regulation (Shleifer, 1985) to political competition in multijurisdiction elections (Besley and Case, 1995).

Most of the existing research on the RPE puzzle proposes one of three possible explanations:

(i) It is incorrect to assume that the incentives of CEOs derive solely from their compensation, because the rest of their wealth also creates implicit incentives;

(ii) Product market interactions may have a significant impact on optimal compensation schemes;

(iii) Optimal contracting in executive labor markets does not necessarily lead to RPE provisions.

Two exponents of the first approach are Garvey and Milbourn (2003) and Core and Guay (2003) who observe that the exposure to risk of executive compensation packages is only part of executives' total exposure to risk. When executive compensation does not filter out market risk, the executive can reduce his exposure to market risk by reducing the exposure to risk of the rest of his financial wealth. Garvey and Milbourn (2003) find some evidence of RPE for younger executives, who are likely to be less able to filter out market risk because they have less wealth.

The second approach has been followed by Salas Fumás (1992) who pointed out that when product markets are imperfectly competitive, compensation schemes that make a manager's pay increasing in rival firms' performance measures may be desirable because they soften competition. This idea has been pursued by Aggarwal and Samwick (1999a) and by Joh (1999) who have found empirical evidence of managerial compensation increasing in industry performance, in particular in more competitive environments. Aggarwal and Samwick (1999a) reconcile this finding with price rather than quantity competition and Joh (1999) underlines that the usefulness of strategic group performance evaluation (in opposition to RPE) for sustaining collusion in product markets is larger in a more competitive setting.

The two main exponents of the third approach are Himmelberg and Hubbard (2000) and Oyer (2004). Himmelberg and Hubbard (2000) point out that when observable aggregate shocks change the marginal values of CEO services to firms, a CEO's compensation depends on the 
aggregate shock for at least two reasons. First, it is optimal to make pay dependent on a performance measure that is benchmarked against the aggregate shock. Second, if a favorable aggregate shock increases the marginal value of effort, more effort is required when the aggregate shock is favorable and the fixed part of compensation is increased to meet the participation constraint. The first component calls for compensation that decreases in the aggregate shock. But the second component requires that compensation is higher when the aggregate shock is high and may more than compensate the first.

Oyer (2004) concentrates his attention on the participation constraint and points out that there may be positive correlation between workers' outside opportunities and firms' market values. In such an environment, if it is costly to revise labor contracts, a profit sharing scheme that does not filter out aggregate risk is employed as a way to index compensation to market conditions and, therefore, automatically meet workers' participation constraints.

Our research obviously belongs to the third approach and is in particular similar to Himmelberg and Hubbard (2000) because we too allow for the marginal impact of effort to depend on an aggregate state. But to understand our contribution, it is important to observe that we can explain the evidence of one-sided RPE. By contrast, neither Himmelberg and Hubbard (2000) nor Oyer (2004) can explain one-sided RPE because they both find that compensation may be increasing or decreasing in the aggregate shock, but the sign of this relationship is independent of the firm's individual (unfiltered) performance measure.

The paper is organized as follows. Section 2 presents the model. Section 3 characterizes the optimal contract that induces a high level of effort. Section 4 shows that the joint probability distributions that are considered in Section 3 can be derived from a simple example and discusses extensions and applications of our results. Section 5 concludes.

\section{The model}

Consider two firms, $i=1,2$. Firm $i$ is formed by risk-neutral owner $i$ and risk-averse manager $i$. Owner $i$ makes a take-it-or-leave-it contract offer to manager $i{ }^{7}$ A contract is a salary schedule contingent on the public output realizations that follow acceptance. If manager $i$ accepts owner $i$ 's offer, he joins the firm and has to choose whether to exert effort, $e=1$, or not, $e=0$. Managers 1 and 2 have the same preferences, described by the following Bernoulli utility function

$$
V_{i}\left(e_{i}, w\right)=U(w)-g\left(e_{i}\right) .
$$

For the sake of simplicity we assume that $U($.) is twice continuously differentiable, strictly increasing, strictly concave, and that the Inada conditions hold, $\lim _{w \rightarrow 0^{+}} U^{\prime}(w)=+\infty$, $\lim _{w \rightarrow+\infty} U^{\prime}(w)=0$. We assume that $g(1)>g(0)$. We denote reservation utility of managers by $\bar{U}$.

After accepting an offer from owner $i$, manager $i$ exerts effort or shirks, after which an output realization, $y_{i}$, is publicly observed. The realization can be success with output $y_{i}=S>0$ or failure with output $y_{i}=F<S$. The probability distribution of firm $i$ 's output realization depends on manager $i$ 's effort choice, $e_{i} \in\{0,1\}$, and on an unobservable aggregate state of nature, $\Pi \in$

\footnotetext{
7 We consider the case of two different principals, each designing a contract for his own manager, but our results do not derive from the fact that the two principals make independent decisions. The same results would be obtained even if a single principal offered contracts to each of the two managers.
} 
$\{\underline{\Pi}, \bar{\Pi}\}$. We denote the probability of state $\bar{\Pi}$ by $\bar{\beta}$ and the probability of state $\underline{\Pi}$ by $\beta=1-\bar{\beta}$. If manager $i$ shirks, the probability of success is

$$
\operatorname{Pr}\left(y_{i}=S \mid e_{i}=0, \Pi\right)= \begin{cases}\bar{p} & \text { if } \Pi=\bar{\Pi}, \\ \underline{p} & \text { if } \Pi=\underline{\Pi} .\end{cases}
$$

We assume that $p<\bar{p}$ and we therefore term aggregate states $\underline{\Pi}$ and $\bar{\Pi}$ the unfavorable and the favorable aggregate state, respectively. If manager $i$ exerts effort, the probability of success is

$$
\operatorname{Pr}\left(y_{i}=S \mid e_{i}=1, \Pi\right)= \begin{cases}\bar{p}+\bar{\gamma} & \text { if } \Pi=\bar{\Pi}, \\ \underline{p}+\underline{\gamma} & \text { if } \Pi=\underline{\Pi} .\end{cases}
$$

We call $\bar{\gamma}$ the marginal return of effort in the favorable state and $\gamma$ the marginal return of effort in the unfavorable state. Notice that we do not need to assume that $\bar{\gamma}>\underline{\gamma}$. Because we call $\underline{\Pi}$ and $\bar{\Pi}$ the unfavorable and the favorable aggregate state, it is natural to assume that $\bar{p}+\bar{\gamma}>\underline{p}+\underline{\gamma}$, but this is not essential for our results. Notice also that the probability distribution of the output realization of firm $i$ is independent of the effort choice of manager $j \neq i$. Notice finally that for simplicity we assume that the two managers have identical probability distributions, but this is not important for our result.

As mentioned above, a contract offered by an owner to a manager is a promise to pay a salary that is contingent on subsequent public history, i.e., on both firms' output realizations. It is useful to remark that, conditional on the aggregate state, the output realizations of the two firms are independent. But if no conditioning on the aggregate state is performed, output realizations are not independent, because they both depend on the common aggregate shock. This means that the simple informational structure described above portrays a situation in which, given that the aggregate state is not observable, both output realizations convey information on each manager's likely effort choice and this implies that it may be in the interest of each of the owners to make the pay of his manager dependent on the output realizations of both firms.

We denote the public history following acceptance by both managers by

$$
\left(y_{1}, y_{2}\right) \in Y=\{(F, F),(S, F),(F, S),(S, S)\} .
$$

With an abuse of notation, we also denote history $\left(y_{1}, y_{2}\right)=(F, F)$ by $\left(F_{1}, F_{2}\right)$, and so on. We denote a contract by

$$
w_{i}=\left(w_{i}\left(F_{1}, F_{2}\right), w_{i}\left(S_{1}, F_{2}\right), w_{i}\left(F_{1}, S_{2}\right), w_{i}\left(S_{1}, S_{2}\right)\right) \in \mathbb{R}_{+}^{4}
$$

where $w_{i}\left(F_{1}, F_{2}\right)$ denotes the salary payment to manager $i$ if both firms' output realizations are $F$, and so on.

The equilibrium concept we use is subgame perfect Nash equilibrium.

\section{Equilibrium contracts}

In the rest of the paper, we will center our attention on equilibria in which both owners 1 and 2 offer a contract that induces the manager to exert effort. To characterize equilibrium contracts, we therefore simply need to find for each of the two owners the contract that has the lowest cost among the contracts that are (i) accepted by the manager; (ii) such that the manager weakly prefers exerting effort to shirking. In other words, for each of the two firms, offered contracts minimize the expected wage payments to executives subject to individual rationality and incentive compatibility constraints. 
The following proposition contains the main result of the paper. To simplify the presentation, we ignore the cases in which $\frac{\bar{\gamma}}{\underline{\gamma}}=\frac{1-\bar{p}}{1-\underline{p}}$ and $\frac{\bar{\gamma}}{\underline{\gamma}}=\frac{\bar{p}}{\underline{p}}$.

Proposition 1. Suppose that in equilibrium owner $i$ offers manager $i$ a contract that induces manager $i$ to exert effort, $i=1,2$. Then, for $i=1,2$ and $j \neq i$

(1) $w_{i}\left(S_{i}, S_{j}\right)>w_{i}\left(F_{i}, S_{j}\right)$ and $w_{i}\left(S_{i}, F_{j}\right)>w_{i}\left(F_{i}, F_{j}\right)$.

(2) If $\frac{\bar{\gamma}}{\gamma}<\frac{1-\bar{p}}{1-p}, w_{i}\left(S_{i}, S_{j}\right)<w_{i}\left(S_{i}, F_{j}\right)$ and $w_{i}\left(F_{i}, S_{j}\right)>w_{i}\left(F_{i}, F_{j}\right)$.

(3) If $\frac{\overline{\bar{\gamma}}}{\underline{\gamma}} \in\left(\frac{1-\bar{p}}{1-\underline{p}}, \frac{\bar{p}}{\underline{p}}\right), w_{i}\left(S_{i}, S_{j}\right)<w_{i}\left(S_{i}, F_{j}\right)$ and $w_{i}\left(F_{i}, S_{j}\right)<w_{i}\left(F_{i}, F_{j}\right)$.

(4) If $\frac{\overline{\bar{\gamma}}}{\underline{\underline{\gamma}}}>\frac{\bar{p}}{\underline{p}}, w_{i}\left(S_{i}, S_{j}\right)>w_{i}\left(S_{i}, F_{j}\right)$ and $w_{i}\left(F_{i}, S_{j}\right)<w_{i}\left(F_{i}, F_{j}\right)$.

Proof. Without loss of generality consider firm 1. If in equilibrium owner 1 offers manager 1 a contract $w_{1}\left(y_{1}, y_{2}\right)$ that induces manager 1 to exert effort, $e_{1}=1, w_{1}\left(y_{1}, y_{2}\right)$ must be a solution to the following problem:

$$
\begin{aligned}
\min _{w_{1} \in \mathbb{R}_{+}^{4}} & \sum_{y \in Y} \operatorname{Pr}\left(y_{1}, y_{2} \mid e_{1}=1, e_{2}=1\right) w_{1}\left(y_{1}, y_{2}\right) \\
\text { s.t. } & \sum_{y \in Y} \operatorname{Pr}\left(y_{1}, y_{2} \mid e_{1}=1, e_{2}=1\right) U\left(w_{1}\left(y_{1}, y_{2}\right)\right)-g(1) \geqslant \bar{U}, \\
& \sum_{y \in Y} \operatorname{Pr}\left(y_{1}, y_{2} \mid e_{1}=1, e_{2}=1\right) U\left(w_{1}\left(y_{1}, y_{2}\right)\right)-g(1) \\
\geqslant & \sum_{y \in Y} \operatorname{Pr}\left(y_{1}, y_{2} \mid e_{1}=0, e_{2}=1\right) U\left(w_{1}\left(y_{1}, y_{2}\right)\right)-g(0) .
\end{aligned}
$$

Because of the assumptions on the utility function, the solution to this problem is interior and satisfies the following first order conditions:

$$
\frac{1}{U^{\prime}\left(w_{1}\left(y_{1}, y_{2}\right)\right)}=\lambda_{1}+\mu_{1}\left(1-\frac{\operatorname{Pr}\left(y_{1}, y_{2} \mid e_{1}=0, e_{2}=1\right)}{\operatorname{Pr}\left(y_{1}, y_{2} \mid e_{1}=1, e_{2}=1\right)}\right)
$$

for all $y \in Y$. Because at a solution of (1), constraints (2) and (3) are binding and the Lagrange multipliers are strictly positive, parts (1)-(4) follow from (4) and

$$
0<\frac{1-\bar{p}}{1-\underline{p}}<1<\frac{\bar{p}}{\underline{p}}
$$

To understand Proposition 1 recall first that an optimal contract makes a higher payment whenever the likelihood of having exerted effort is higher. Part (1) of Proposition 1 establishes that to induce a manager to exert effort, his salary has to be increasing in own performance, for any possible performance level of the other firm. This is a simple consequence of the fact that the probability distribution satisfies the Monotone Likelihood Ratio property with respect to own performance, so that the likelihood of having exerted effort is higher if own performance is good rather than bad.

Parts (2)-(4) of Proposition 1, on the other hand, state that the salary payment made to a manager is not necessarily monotonic in the output of the other firm. 
To understand this, consider part (4) first. If $\frac{\bar{\gamma}}{\underline{\gamma}}>\frac{\bar{p}}{\underline{p}}, \bar{\gamma}$ is sufficiently larger than $\underline{\gamma}$ or, in words, the marginal return of effort is sufficiently larger in the favorable than in the unfavorable aggregate state. In such an environment if manager 1's output is high, the likelihood of him having exerted effort is higher if the aggregate state is favorable than if it is unfavorable. But because a high level of output of manager 2 indicates that a favorable aggregate state is more likely, the likelihood of manager 1 having exerted effort is higher if both outputs are high than if manager 1's output is high and manager 2's is low,

$$
\frac{\operatorname{Pr}\left(S_{1}, S_{2} \mid e_{1}=1, e_{2}=1\right)}{\operatorname{Pr}\left(S_{1}, S_{2} \mid e_{1}=0, e_{2}=1\right)}>\frac{\operatorname{Pr}\left(S_{1}, F_{2} \mid e_{1}=1, e_{2}=1\right)}{\operatorname{Pr}\left(S_{1}, F_{2} \mid e_{1}=0, e_{2}=1\right)} .
$$

Because (5) is equivalent to

$$
\frac{\operatorname{Pr}\left(F_{1}, S_{2} \mid e_{1}=1, e_{2}=1\right)}{\operatorname{Pr}\left(F_{1}, S_{2} \mid e_{1}=0, e_{2}=1\right)}<\frac{\operatorname{Pr}\left(F_{1}, F_{2} \mid e_{1}=1, e_{2}=1\right)}{\operatorname{Pr}\left(F_{1}, F_{2} \mid e_{1}=0, e_{2}=1\right)},
$$

if manager 1's output is low, the likelihood of him having exerted effort is higher if manager 2's output is also low than if it is high. For this reason, if a manager's output is low, his compensation is higher if the other manager's output is also low than if it is high. Therefore, if the marginal returns of managerial effort are sufficiently increasing in the aggregate state, equilibrium contracts exhibit one-sided RPE, because a manager's pay is increasing in the performance benchmark when own performance is good and decreasing when it is bad.

Consider now part (2). If $\frac{\bar{\gamma}}{\gamma}<\frac{1-\bar{p}}{1-\underline{p}}, \bar{\gamma}$ is sufficiently smaller than $\underline{\gamma}$ or, in words, the marginal return of effort is sufficiently larger in the unfavorable than in the favorable aggregate state. Similar arguments show that in such an environment, a manager's compensation is increasing in peer performance when own performance is low $\left(F_{1}\right)$. But when own performance is high $\left(S_{1}\right)$, a manager's compensation is decreasing in peer performance. In this case, therefore, performance is benchmarked against peer performance when own performance is high, but reverse benchmarking takes place when own performance is low. Under the condition of part (2), we therefore obtain a result that can explain the lack of RPE but cannot account for the evidence of one-sided RPE.

Finally, consider part (3). If $\frac{\bar{\gamma}}{\underline{\gamma}} \in\left(\frac{1-\bar{p}}{1-\underline{p}}, \frac{\bar{p}}{\underline{p}}\right)$, the marginal returns of effort are relatively similar in the unfavorable and in the favorable aggregate state. In this case, the likelihood of a manager having exerted effort is always higher when the other manager's output is low and a manager's compensation is monotonically decreasing in the performance benchmark.

\subsection{Example}

Consider the case in which $U(w)=\log (w), \bar{p}=0.2, \underline{p}=0.15, \bar{\gamma}=0.2, \underline{\gamma}=0.05, \bar{\beta}=0.6$, $g(0)=0.1, g(1)=0.2$, and $\bar{U}=0$. Notice that this implies that we are in the condition of part (4) of Proposition 1. Suppose that both managers exert effort in equilibrium, $e_{1}=e_{2}=1$. From (4) we obtain that the least cost contract that induces a manager to exert effort (when the other manager also accepts a contract that induces him to exert effort) is

$$
w=\left(w\left(F_{1}, F_{2}\right), w\left(S_{1}, F_{2}\right), w\left(F_{1}, S_{2}\right), w\left(S_{1}, S_{2}\right)\right)=(1.00,1.95,0.91,2.03) .
$$

Notice that the expected salary payment under $w$ is 1.2942 and that the salary payment necessary to induce manager $i$ to accept a contract and play $e_{i}=0$ is 1.1052 . This means that for a manager to exert effort in equilibrium, it is necessary that the increase in the expected value 
of output due to his effort is at least as large as the increase in the expected compensation cost necessary to induce him to exert effort. Straightforward calculations show that $S-F \geqslant 1.35$ is necessary for an equilibrium to exist whereby both owners offer $w$ to their managers, both managers accept the offer and play $e_{1}=e_{2}=1 .^{8}$ When $S-F \geqslant 1.35$, therefore, there is an equilibrium in which both owners offer $w$ to their respective managers and they both accept. Notice that $w\left(F_{1}, F_{2}\right)>w\left(F_{1}, S_{2}\right)$ and $w\left(S_{1}, F_{2}\right)<w\left(S_{1}, S_{2}\right)$. This means that there is a tendency for managers to be rewarded more generously when their performances are in line with each other (they both succeed, or they both fail), rather than when the other manager's performance is below par (when he fails). As was argued before, this may help explain the apparent lack of RPE considerations and the evidence of one-sided RPE in CEO compensation.

\subsection{Discussion}

The results of this section can be read in two ways. A minimal reading is that we characterize conditions under which executive compensation fails to be monotonically decreasing with respect to performance benchmarks (the cases mentioned in parts (2) and (4) of Proposition 1). An alternative view is that we characterize the conditions under which executive compensation is decreasing in the performance benchmark when own performance is below expectations and increasing when own performance is above expectations, or in other words, that executive compensation exhibits one-sided RPE (the case mentioned in part (4) of Proposition 1). These characterizations are made easy by our simple setting with only two effort levels and only two output realizations. But the qualitative results do not depend on the setting and would also obtain in a more general setting with multiple effort levels and/or multiple output realizations.

To make compensation not monotonically decreasing in the performance benchmark, it is enough that the action that the principal wants to implement has the property that it leads to a change in the probability of at least one realization of output that depends sufficiently on the aggregate state. To obtain one-sided RPE, on the other hand, one would need to require that the action that the principal wants to implement leads to increases in the probabilities of $a$ sufficient number of above-average realizations of output that are adequately larger when the aggregate state is favorable than when it is unfavorable.

Our results have been obtained for a simple static setting, but the same characterizations of equilibrium contracts can be easily derived for a dynamic setting in which risk can be spread intertemporally. For example, if the firm and the executive have the ability to commit to longterm contracts, the executive consumes all his income in each period and decides the effort level to exert at the beginning of each period (possibly after observing previous period realizations), the same conditions as in Proposition 1 characterize the response of executive compensation to own performance and to the performance benchmark in each period. ${ }^{9}$

Notice that assuming an executive consumes all his income in each period is equivalent to assuming that the executive cannot save or borrow, or that his savings are monitored by the firm. Making such an assumption seems appropriate in this setting for two reasons. First, the dynamic moral hazard literature has clarified that if an agent can save or borrow unobserved by the principal, an additional dimension of information asymmetry is introduced in the con-

\footnotetext{
8 When $S-F>1.37$, this equilibrium is unique. When $S-F \in[1.35,1.37]$, there exists also another pure strategy equilibrium in which no manager is induced to exert effort. When $S-F<1.35$, in the unique equilibrium no manager is induced to exert effort.

9 A proof for the case of two periods is available from the authors upon request.
} 
tinuation contracting problem that makes long-term contracts not renegotiation-proof and not spot-implementable. ${ }^{10}$ Second, if an executive trades in financial securities and if these securities allow him to hedge risk, the incentives established by his compensation package may be undermined. Recent literature has clarified that this is an important problem for the design of executive compensation and in particular for the introduction of relative performance evaluation provisions. ${ }^{11}$ We believe that this is an important problem that deserves a dedicated analysis and we therefore choose to abstract from it.

To understand our contribution it is useful to discuss two important modeling differences between our work and that of Himmelberg and Hubbard (2000). First, Himmelberg and Hubbard (2000) analyze the dependence of executive pay on a future individual performance measure (which becomes known after contracting and effort choice) and on a past performance benchmark, i.e., on an aggregate state that becomes observable before contracting. Second, they assume that the marginal value of effort is increasing in the aggregate state, or, in other words, that the increase in the expected value of output realizations deriving from higher effort is increasing in the aggregate state. This means that before contracting it is known whether the environment is one with a high or low marginal value of effort (favorable or unfavorable aggregate state). These assumptions work in the direction of creating a positive relationship between executive compensation and the aggregate state, because when a favorable aggregate state is observed, the principal wants to induce a higher effort and has to compensate the manager for it.

By contrast, we analyze the dependence of executive pay on future measures of both individual performance and performance benchmark, meaning that both are observed only after contracting and effort choice. We also assume that the marginal effect of effort depends on the aggregate state, i.e., that the changes in the probability distributions over output realizations deriving from increased effort depend on the aggregate state, but we are largely agnostic as to whether the aggregate state has an impact on the value of individual output realizations. In other words, our result relies solely on the statistical information on the likely effort choice contained in the performance benchmark and not on the value attached to output realizations.

These modeling differences imply different views on the relation between executive compensation and performance benchmarks. Recall first that RPE is normally regarded as a way to make compensation depend on future measures of own performance and performance benchmarks. Because the work of Himmelberg and Hubbard (2000) concentrates on how contracts depend on past realizations of the aggregate state, it has no implications on RPE. By contrast our paper is concerned on the way in which optimal contracts shape the dependence of compensation on future measures of own performance and performance benchmarks and shows that under reasonable conditions optimal compensation violates the recommendations of RPE.

\section{Extensions}

The purpose of this section is to show (i) that the properties of the joint probability distributions that have been considered in Section 3 can be derived from a simple example; (ii) that the results of Section 3 are robust because they also hold if the aggregate state is observable and/or if adverse selection rather than moral hazard is the source of the agency problem; (iii) that our results have interesting applications to environments different from labor contracts.

\footnotetext{
10 See, for example, Chiappori et al. (1994).

11 See, for example, Acharya and Bisin (2005), Bisin et al. (2006), and Garvey and Milbourn (2003).
} 


\subsection{How can the described technology arise?}

The purpose of this subsection is to show that the joint probability distribution over output realizations that we have considered naturally arise in simple setting. Suppose that each firm $i$ has two investment projects available, $I$ and $I I$. Each project, if undertaken, has two possible realizations, success, $y_{i}=S>0$, or failure, $y_{i}=F<S$.

An unobservable aggregate state of nature $\Pi \in\{\underline{\Pi}, \bar{\Pi}\}$ determines the probability of success of investment project $I$ for each individual firm. In the favorable aggregate state, $\bar{\Pi}$, the probability of success is $\bar{p} \in(0,1)$ and in the unfavorable aggregate state, $\underline{\Pi}$, the probability of success is $\underline{p} \in(0, \bar{p})$. In a similar way, the aggregate state of nature $\Pi \in\{\underline{\Pi}, \bar{\Pi}\}$ determines the probability of success of individual firms' investment project $I I$. In the favorable aggregate state, $\bar{\Pi}$, the probability of success is $\bar{q} \in(0,1)$ and in the unfavorable aggregate state, $\underline{\Pi}$, the probability of success is $q \in(0, \bar{q})$. We also assume that project $I$ is ex ante superior to project $I I$.

When manager $i$ exerts effort, $e_{i}=1$, he is able to forecast the realization of project $I$ without error. $^{12}$ If he shirks, $e_{i}=0$, he is unable to improve his forecast of the realization of project $I$ beyond the prior probability distribution. For the sake of simplicity, we assume that, regardless of whether he exerts effort or not, manager $i$ is not able to make any forecast about the realization of project $I I$. Given that project $I$ is ex ante superior to project $I I$, this assumption could be justified if, for instance, the manager could devote a limited amount of time to the analysis of investment projects and it were optimal for him to dedicate it to project $I$.

Notice that conditional on an effort level, the manager's choice between projects $I$ and II only depends on his information and on the contract he accepted and that a sufficient condition for the manager to make an efficient project choice conditional on his information is that his compensation is increasing in own performance. For the moment, we conjecture that this is the case and we will verify it later. Under this conjecture, the probability distribution of firm $i$ 's output realization depends on manager $i$ 's effort choice, $e_{i} \in\{0,1\}$, and on the unobservable aggregate state $\Pi \in\{\underline{\Pi}, \bar{\Pi}\}$ as follows. If manager $i$ shirks, he chooses project $I$, the ex ante superior project. The probability of success conditional on the aggregate state is therefore

$$
\operatorname{Pr}\left(y_{i}=S \mid e_{i}=0, \Pi\right)= \begin{cases}\bar{p} & \text { if } \Pi=\bar{\Pi}, \\ \underline{p} & \text { if } \Pi=\underline{\Pi} .\end{cases}
$$

If manager $i$ exerts effort, he knows in advance whether project $I$ will succeed or not. If he forecasts success, he chooses project $I$. But if he anticipates a failure of project $I$, he chooses project $I I$. With effort, therefore, the probability of success conditional on the aggregate state is

$$
\operatorname{Pr}\left(y_{i}=S \mid e_{i}=1, \Pi\right)= \begin{cases}\bar{p}+\bar{q}(1-\bar{p}) & \text { if } \Pi=\bar{\Pi}, \\ \underline{p}+\underline{q}(1-\underline{p}) & \text { if } \Pi=\underline{\Pi} .\end{cases}
$$

Using the notation of Section 3, we therefore have $\bar{\gamma}=\bar{q}(1-\bar{p})$ and $\underline{\gamma}=\underline{q}(1-\underline{p})$.

Suppose now that in equilibrium both firms offer their managers contracts that induce them to exert effort. Simple algebra shows that the least cost salaries that induce managers 1 and 2 to exert effort are increasing in own performance and therefore the conjecture that managers 1 and 2 make efficient project choices (conditional on the information they have) is verified. We can now

\footnotetext{
12 This assumption is made only for simplicity of exposition, but is by no means necessary. The same qualitative results would obtain so long as the signal that the manager receives when exerting effort has at least one realization that makes the posterior probability of success of $I$ strictly smaller than the probability of success of $I I$.
} 
make use of the results of Section 3. For instance, the marginal return of effort is increasing in the aggregate state when

$$
\frac{\bar{q}(1-\bar{p})}{\underline{q}(1-\underline{p})}>\frac{\bar{p}}{\underline{p}}
$$

When condition (6) holds, $w_{1}\left(S_{1}, F_{2}\right)<w_{1}\left(S_{1}, S_{2}\right)$. It is useful to rewrite condition (6) as follows

$$
\frac{\bar{q}(1-\bar{p})}{\bar{p}}>\frac{\underline{q}(1-\underline{p})}{\underline{p}}
$$

because it shows that for manager 1 to be paid more when both firms succeed rather than when firm 1 succeeds and firm 2 fails, it is necessary and sufficient that the relative likelihood of success deriving from effort is higher in the favorable aggregate state. The reason is that, when the manager makes efficient project choices, success is relatively more likely to derive from project $I I$ rather than $I$ in state $\bar{\Pi}$ than in state $\underline{\Pi}$. Recalling that a manager chooses project $I I$ only when he exerts effort, and that a manager is rewarded more generously when there is more compelling evidence that he chose the appropriate effort levels, therefore explains why the manager's compensation is higher when both firms succeed than when only firm 1 succeeds.

\subsection{An observable aggregate state}

Section 2 introduced a model in which an unobservable aggregate state influences the probability distributions over outcomes. Because the aggregate state is unobservable, the least cost contract that induces manager $i$ to exert effort also depended on the output realization of firm $j \neq i$. We now analyze the case in which the aggregate state is observable. This is useful for two reasons. First, it clarifies that our results are independent of whether the aggregate state is observable or not. Second, it indicates how compensation should respond to public observables such as output prices, interest rates, or exchange rates.

Suppose that the aggregate state is publicly observed at the same time as the individual performance of each individual firm. In such a situation, it is easy to verify that in an equilibrium in which a manager chooses to exert effort, the least cost contracts that induces him to do so depends only on own performance and on the realization of the aggregate state

$$
w=(w(F, \underline{\Pi}), w(S, \underline{\Pi}), w(F, \bar{\Pi}), w(S, \bar{\Pi}))
$$

and that we obtain

$$
w(S, \bar{\Pi})>w(S, \underline{\Pi}) \text { if and only if } \frac{\bar{\gamma}}{\underline{\gamma}}>\frac{\bar{p}}{\underline{p}}
$$

and

$$
w(F, \bar{\Pi})>w(F, \underline{\Pi}) \text { if and only if } \quad \frac{\bar{\gamma}}{\underline{\gamma}}<\frac{1-\bar{p}}{1-\underline{p}} .
$$

In other words, when the aggregate state is observable, the results are qualitatively identical to the results of Section 3 in which the aggregate state was unobservable and statistical information about it was obtained by the realizations of output of other firms.

In the numerical case described in the example of Section 3.1, the observability of the aggregate state leads to the following least cost salary which induces managers to exert effort:

$$
(w(F, \underline{\Pi}), w(S, \underline{\Pi}), w(F, \bar{\Pi}), w(S, \bar{\Pi}))=(1.20,1.59, .87,1.90) .
$$


Simple computations show that the expected salary payment to a manager is 1.2804 , which is less than 1.2942 , the expected salary payment to a manager when only individual output realizations are observed and when both managers exert effort. In other words, the incremental information provided by the observability of the aggregate state lowers the cost of inducing managers to exert effort but leaves the qualitative properties of salaries unchanged.

\subsection{Adverse selection}

In this paper, we show that a simple moral hazard model can lead to a failure of RPE and to one-sided RPE. But, as is commonly the case with contracts in asymmetric information environments, similar results could be obtained in an adverse selection setting. ${ }^{13}$ In an earlier version of this paper, Celentani and Loveira (2004), we studied relative performance evaluation when firms compete for risk-averse managers who have private information about their individual abilities. We assumed that the probability distribution over a firm's performance depends on the ability of its manager, but also on a common aggregate state (when the aggregate state is favorable, a firm is more likely to experience success). To avoid unnecessary complications, we assumed that the individual performance and the aggregate state are both publicly observable and we allowed executive compensation to be made dependent on both to sort executives of different abilities.

We found that in contracts accepted in equilibrium, executive compensation is increasing in own performance, but may also be increasing in industry performance. The intuition behind this result is similar to one discussed in this paper. Managers of different abilities generate different probability distributions over states, i.e., over pairs of individual and aggregate performance. This implies that no equilibrium exists in which both types of manager accept the same contract. If this were the case, a firm could profit from screening out a good manager by offering a contract that increases compensation in a state which is relatively more likely for the good manager and decreases it in a state which is relatively less likely for him.

If an equilibrium exists, then, it has to be separating in the sense that the contracts accepted by the two types are different. These results are reminiscent of the insurance market with adverse selection studied by Rothschild and Stiglitz (1976) and Wilson (1977). As in that case, risk aversion implies that in equilibrium, the bad manager accepts a contract that fully insures him. The contract accepted by the good manager is the contract that the good manager most prefers among the ones that break even and are such that the bad manager prefers his own contract.

In Rothschild and Stiglitz (1976), the good type has incomplete insurance and therefore has higher consumption in the state that is relatively more likely for him, i.e., the no-loss state. In a similar way, we find that compensation to the good manager is higher in states that are relatively more likely for him than for the bad type. But we also find that, because of correlation between market and individual outcomes, the likelihood of a given level of own performance with a favorable aggregate state relative to the same level of performance with an unfavorable aggregate state may be higher for a good manager than for a bad one. This occurs, for instance, when the marginal return of ability - the increase in the probability of success generated by a good manager - is sufficiently higher in the favorable than in the unfavorable aggregate state. In such a case, the contract accepted in equilibrium by a good manager stipulates that, conditional on own success, executive compensation is higher with a favorable than with an unfavorable

\footnotetext{
13 Recent research has tried to distinguish between moral hazard and adverse selection in insurance data. See, for instance, Abbring et al. (2003) and their references.
} 
aggregate state. In other words, we find that executive compensation is increasing in the firm's absolute performance but is not necessarily decreasing with industry performance.

The moral hazard model we use in the present paper helps explain in a simple way why executive compensation may lack RPE considerations and may even exhibit one-sided RPE. But the adverse selection counterpart that we have briefly discussed is also important because many authors believe that executive compensation should be viewed more as a way to retain executives with superior abilities or induce them to make decisions in the interest of shareholders, than as an attempt to provide lazy managers with incentives to work hard. ${ }^{14}$

\subsection{Pay for luck}

The results of the previous two subsections have implications for the debate on the response of executives' compensation to "observable luck," i.e., to publicly observable events that are beyond the executives' control. In a case study of the oil industry, for instance, Bertrand and Mullainathan (2001) find that CEOs' pay is increasing in the price of oil. They conclude that this evidence is inconsistent with an optimal contracting view and that it can be explained by the fact that CEOs gain effective control of the pay-setting process.

Our results clarify that a simple contracting model can generate these compensation patterns. Consider for instance the case in which the aggregate state $\Pi$ is observable and denote by $\underline{\Pi}$ and $\bar{\Pi}$ the states in which the price of oil is, respectively, low or high. Suppose that a CEO's effort increases the probability of new field discoveries regardless of the price of oil, but that the discoveries are more likely to translate into higher returns if the price of oil is high than if it is low. In such a situation the CEO's effort increases the probability of superior performance more when the price of oil is high than when it is low. If this differential effect is sufficiently large, $\frac{\bar{\gamma}}{\underline{\gamma}}>\frac{\bar{p}}{\underline{p}}$, a contract that makes the CEO's compensation monotonically decreasing in the price of oil cannot be optimal.

To see this suppose that in the least cost contract $w$ that induces effort $w(S, \bar{\Pi}) \leqslant w(S, \underline{\Pi})$. We will argue that there exist a different contract $w^{\prime}$ that retains incentives and has a lower expected cost to the shareholders. Let $w^{\prime}$ be identical to $w$ apart from

$$
\begin{aligned}
& w^{\prime}(S, \bar{\Pi})=w(S, \bar{\Pi})+\mathrm{d} \varepsilon, \\
& w^{\prime}(S, \underline{\Pi})=w(S, \underline{\Pi})+\mathrm{d} \delta,
\end{aligned}
$$

with $\mathrm{d} \varepsilon>0$ and $\mathrm{d} \delta<0$. A sufficient condition for the CEO to exert effort under $w^{\prime}$ is that as compared to $w$ the gain from exerting effort is at least as large as the gain from shirking. Because $w(S, \bar{\Pi}) \leqslant w(S, \underline{\Pi})$ and because of risk aversion a sufficient condition for this to hold is

$$
\frac{\mathrm{d} \varepsilon}{\mathrm{d} \delta} \leqslant-\frac{\operatorname{Pr}\left(S, \underline{\Pi} \mid e_{1}=1\right)-\operatorname{Pr}\left(S, \underline{\Pi} \mid e_{1}=0\right)}{\operatorname{Pr}\left(S, \bar{\Pi} \mid e_{1}=1\right)-\operatorname{Pr}\left(S, \bar{\Pi} \mid e_{1}=0\right)} .
$$

For $w^{\prime}$ to have a lower expected cost than $w$ it is necessary and sufficient that

$$
\frac{\mathrm{d} \varepsilon}{\mathrm{d} \delta}>-\frac{\operatorname{Pr}\left(S, \underline{\Pi} \mid e_{1}=1\right)}{\operatorname{Pr}\left(S, \bar{\Pi} \mid e_{1}=1\right)} .
$$

\footnotetext{
14 According to Murphy (1999, p. 2521), "the reason shareholders entrust their money to self-interested CEOs is based on shareholder beliefs that CEOs have superior skills or information in making investment decisions." For similar arguments, see also Holmström and Ricart i Costa (1986), Ricart i Costa (1989), Core and Guay (2003), or Prendergast (2002).
} 
A necessary and sufficient condition for a contract $w^{\prime}$ to exist that retains incentives and that has a lower expected cost than $w$ is therefore

$$
\frac{\operatorname{Pr}\left(S, \underline{\Pi} \mid e_{1}=1\right)}{\operatorname{Pr}\left(S, \bar{\Pi} \mid e_{1}=1\right)}>\frac{\operatorname{Pr}\left(S, \underline{\Pi} \mid e_{1}=1\right)-\operatorname{Pr}\left(S, \underline{\Pi} \mid e_{1}=0\right)}{\operatorname{Pr}\left(S, \bar{\Pi} \mid e_{1}=1\right)-\operatorname{Pr}\left(S, \bar{\Pi} \mid e_{1}=0\right)}
$$

which is equivalent to $\frac{\bar{\gamma}}{\underline{\gamma}}>\frac{\bar{p}}{\underline{p}}$. In other words, if $\frac{\bar{\gamma}}{\underline{\gamma}}>\frac{\bar{p}}{\underline{p}}$, the terms at which the CEO's compensation in different states can be traded while retaining incentives permit salary payment savings for shareholders whenever $w(S, \bar{\Pi}) \leqslant w(S, \underline{\Pi})$. This shows that under reasonable conditions paying managers for "observable luck" is not the outcome of an agency failure but is a way in which shareholders minimize the cost of hiring managers and providing them with incentives to act in their interest.

Similar results hold in the adverse selection interpretation, if the excess probability of success of a talented CEO is sufficiently larger when the price of oil is high than when it is low.

\subsection{Yardstick competition}

Relative performance considerations are not only used in labor contracts, but also in many different environments. In yardstick regulation schemes, for instance, a regulator uses information from several different firms to provide incentives for each individual firm (see, for example, Shleifer, 1985, or Sobel, 1999). Yardstick schemes are often used in regulated industries such as medical care, telecommunications, or energy. Yardstick comparisons have also been studied in political agency models. Besley and Case (1995), for instance, have studied how the probability of reelection of a US governor depends on his/her performance as evaluated in relation to the performance of neighboring states.

Our results can obviously also be applied to these settings, regardless of whether the source of asymmetric information is moral hazard or adverse selection. This means that while it is clearly sensible to use benchmarking, the rewards in optimal compensation schemes are not necessarily increasing in relative performance and that apparently unappealing schemes, such as one-sided RPE may be optimal. In a regulation setting, for instance, the reimbursements may exhibit a sort of one-sided RPE.

\section{Conclusion}

It is well known that comparative performance information can be used to improve incentives and efficiency in an agency relationship. Yet empirical work on top executive compensation has found no evidence of RPE, but support for one-sided RPE, i.e., for executive compensation that insulates CEOs from bad luck while rewards them for good luck.

This paper shows that if the marginal return of managerial effort depends on an aggregate state, optimal contracts may be consistent with empirical evidence because a manager's compensation may be increasing in the performance of a rival manager. To understand this notice first that superior performance by any manager increases the likelihood of a favorable aggregate state. If the marginal effect of managerial effort is sufficiently larger in the favorable aggregate state, the increase in the likelihood of the favorable aggregate state implied by manager $i$ 's superior performance, in turn increases the likelihood of manager $j$ having exerted effort. Because an optimal contract rewards a manager with a larger payment when observables are consistent with him having exerted the appropriate level of effort, manager $i$ 's superior performance may increase manager $j$ 's compensation. 
Our simple model produces results that have important implications. First, they reconcile the empirical evidence on CEO compensation with theory. Second, they clarify that simple and appealing principles such as not rewarding or punishing executives for events beyond their control are incorrect: we show that it is sensible to reward a manager if another manager succeeds-an event beyond his control. Third, our results are robust in several dimensions; they hold regardless of there being one or multiple principals, irrespective of whether the aggregate state is perfectly observable or not and independently of whether the source of the agency problem is moral hazard or adverse selection. For this reason our results are useful for analyzing top executive compensation, but are also applicable to other forms of implicit or explicit relative performance evaluations, such as tournaments within organizations, yardstick regulation, or political competition.

\section{Acknowledgments}

We are especially grateful to Wolfgang Pesendorfer, Carlos Ponce, Ravi Singh and an Associate Editor for discussions and suggestions. We also wish to thank Pierpaolo Battigalli, Alberto Bennardo, Alberto Bisin, Antonio Cabrales, Maria Gutiérrez, Belén Jerez, Pablo Ruiz-Verdú and seminar participants at Università Bocconi, Universidad Carlos III, Ente Einaudi, Universidade Nova de Lisboa, Universidad de Alicante, Spring Meeting of Young Economists, April 2004, Econometric Society European Meeting 2004. An earlier version of this paper was circulated with the title "What Form of Relative Performance Evaluation?"

\section{References}

Abbring, J.H., Chiappori, P., Heckman, J.J., Pinquet, J., 2003. Adverse selection and moral hazard in insurance: Can dynamic data help to distinguish? Journal of the European Economic Association 1, 512-521.

Abowd, J.M., Kaplan, D., 1999. Executive compensation: Six questions that need answering. Journal of Economic Perspectives $13,145-168$.

Acharya, V., Bisin, A., 2005. Managerial hedging, equity ownership and firm value. Mimeo. New York University.

Aggarwal, R.K., Samwick, A.A., 1999a. Executive compensation, strategic competition, and relative performance evaluation: Theory and evidence. Journal of Finance, LIV, 1999-2043.

Aggarwal, R.K., Samwick, A.A., 1999b. The other side of the tradeoff: The impact of risk on executive compensation. Journal of Political Economy 107, 65-105.

Antle, R., Smith, A., 1986. An empirical investigation of the relative performance evaluation of corporate executives. Journal of Accounting Research 24, 1-39.

Bannister, J.W., Newman, H.A., 2003. Analysis of corporate disclosures on relative performance evaluation. Accounting Horizons 17 (3), 235-246.

Barro, J.R., Barro, R.J., 1990. Pay, performance and turnover of bank CEOs. Journal of Labor Economics 8, $448-481$.

Bebchuk, L.A., 2006. How much does the boss make? Wall Street Journal 18 (January), A10.

Bertrand, M., Mullainathan, S., 2001. Are CEOs rewarded for luck? The ones without principal are. Quarterly Journal of Economics 116, 901-932.

Besley, T., Case, A., 1995. Incumbent behavior: Vote seeking, tax setting and yardstick competition. American Economic Review 85 (1), 25-45.

Bisin, A., Gottardi, P., Rampini, A., 2006. Managerial hedging and portfolio monitoring. Mimeo.

Celentani, M., Loveira, R., 2004. What form of relative performance evaluation? Working paper 744. Department of Economics, Universitat Pompeu Fabra.

Chance, D.M., Kumar, R., Todd, R.B., 2000. The 'repricing' of executive stock options. Journal of Financial Economics 57, 129-154.

Chiappori, P., Macho, I., Rey, P., Salanié, B., 1994. Repeated moral hazard: The role of memory and commitment. European Economic Review 38, 1527-1553.

Core, J.E., Guay, W.R., 2003. When efficient contracts require risk-averse executives to hold equity: Implications for option valuation, for relative performance evaluation, and for the corporate performance debate. Research paper 0332. University of Pennsylvania, Institute for Law \& Economics. 
de Swaan, J.C., Harper, N.W.C., 2003. Getting what you pay for with stock options. The McKinsey Quarterly 1, 2-5. Closing Views.

Dobbs, R.F.C., Koller, T.M., 2000. Stock options aren't enough. The McKinsey Quarterly 3, 190-192.

The Economist, 2002. Is greed good? In: Capitalism and its troubles. A survey of international finance. May 16, 2002, pp. 23-26.

The Financial Economist Roundtable, 2003. The controversy over executive compensation. Mimeo. Available from http://www.luc.edu/orgs/finroundtable/.

Garvey, G.T., Milbourn, T.T., 2003. Incentive compensation when executives can hedge the market: Evidence of relative performance evaluation in the cross section. Journal of Finance 58 (4), 1557-1582.

Garvey, G.T., Milbourn, T.T., 2006. Asymmetric benchmarking in compensation: Executives are rewarded for good luck but not penalized for bad, Journal of Financial Economics, in press.

Gibbons, M., Murphy, K.J., 1990. Relative performance evaluation for chief executive officers. Industrial and Labour Relations Review 43, 30-52.

Hall, B., Liebman, J., 1998. Are CEOs really paid like bureaucrats? Quarterly Journal of Economics 113, 653-691.

Himmelberg, C.P., Hubbard, R.G., 2000. Incentive pay and the market for CEOs: An analysis of pay-for-performance sensitivity. Mimeo. Columbia University.

Holmström, B., Ricart i Costa, J., 1986. Managerial incentives and capital management. Quarterly Journal of Economics $101,835-860$.

Janakiraman, S.N., Lambert, R.A., Larcker, D.F., 1992. An empirical investigation of the relative performance evaluation hypothesis. Journal of Accounting Research 30, 53-78.

Joh, S.W., 1999. Strategic managerial incentive compensation in Japan: Relative performance evaluation and product market collusion. Review of Economics and Statistics 81, 303-313.

Murphy, K.J., 1999. Executive compensation. In: Ashenfelter, O., Card, D. (Eds.), Handbook of Labor Economics, vol. 3. North-Holland, Amsterdam.

Oyer, P., 2004. Why do firms use incentives that have no incentive effects? Journal of Finance 59, 1619-1649.

Prendergast, C., 1999. The provision of incentives in firms. Journal of Economic Literature 37, 7-63.

Prendergast, C., 2002. The tenuous trade-off between risk and incentives. Journal of Political Economy 110, 1071-1102.

Rappaport, A., 1999. New thinking on how to link executive pay with performance. Harvard Business Review, MarchApril, 91-101.

Ricart i Costa, J., 1989. On managerial contracting with asymmetric information. European Economic Review 33 (9), $1805-1829$.

Rosen, S., 1992. Contracts and the market for executives. In: Werin, L., Wijkander, H. (Eds.), Contract Economics. Blackwell, Oxford.

Rothschild, M., Stiglitz, J.E., 1976. Equilibrium in competitive insurance markets: An essay on the economics of perfect information. Quarterly Journal of Economics 90 (4) (September), 629-649.

Salas Fumás, V., 1992. Relative performance evaluation of management. International Journal of Industrial Organization 10, 473-489.

Shleifer, A., 1985. A theory of yardstick competition. RAND Journal of Economics 16 (3), 319-327.

Sobel, J., 1999. A re-examination of yardstick competition. Journal of Economics and Management Strategy 8, 33-60.

Wilson, C., 1977. A model of insurance markets with incomplete information. Journal of Economic Theory 16, 167-207. 